\title{
ASSESSMENT OF THE RESPONSE REDUCTION FACTORS OF PLAN-IRREGULAR RC BUILDINGS
}

\author{
JUAN CARLOS VIELMA PÉREZ ${ }^{1} \&$ MARÍA MANUELA MULDER MONTES DE OCA ${ }^{2}$ \\ ${ }^{1}$ Civil Engineering School, Pontificia Universidad Católica de Valparaíso, Chile \\ ${ }^{2}$ Universidad Centroccidental Lisandro Alvarado, Venezuela
}

\begin{abstract}
Lessons learned in past earthquakes show that the catastrophic failure of many buildings has been due to their irregularity. For this reason, most seismic-resistant design codes prescribe a series of recommendations that attempt to limit the irregularity of structures. One of the most common types of irregularities in buildings is plan irregularity especially that which occurs when there are plan re-entrant, for reasons of architectural design. In this work the evaluation of the response reduction factor of low-rise buildings, located in a zone of high seismic hazard, is carried out. The methodology applied is the adaptation of the FEMA P695 which requires the use of dynamic non-linear analysis for the assessment of the response reduction factors. The results show that the response reduction factors prescribed by the code provide a safe design, because the calculated coefficients satisfy the minimum acceptable values obtained by applying the FEMA P695 methodology.

Keywords: response reduction factor, plan irregular building, non-linear analysis, FEMA P695.
\end{abstract}

\section{INTRODUCTION}

In the current seismic calculation procedures, seismic design forces are determined by the hazard represented by the reduced elastic spectrum by a response reduction factor $(R)$, which allows to introduce the incursion of structures into the non-linear range of behavior, under the action of strong ground motions [1]. In the particular case of the Venezuelan seismic code, response reduction factors are prescribed according to the structural typology, the materials that compose it, the degree of detail and the regularity of the structural configuration. Structural irregularity should be in elevation or in plan irregularity. According to the Venezuelan seismic code [2], four type of plan irregularity exist:

- Great eccentricity

- High torsional risk

- Non-orthogonal structural system

- Flexible diaphragm

For buildings classified according to the two first irregularities, a reduction of $25 \%$ must be performed to the response reduction factors showed in Table 1 . Note that the ductility level is shown from the highest (ND3) to the lowest (ND1), in descending order, for the different structural types considered in Venezuela (framed buildings are classified as type I). Additionally, structures must be modelled using flexible diaphragm if, among other reasons, "a significant number of plants have re-entrants whose length exceeds $40 \%$ of the dimension of the smallest rectangle attached to the plant, measured parallel to the direction of the re-entrant; or when such re-entrants exceed $30 \%$ of the area of said circumscribed rectangle" [2]. However, for large re-entrants, the penalty applied according to the standard may not affect the value of $R$.

Recognized researchers have made observations on the analytical procedures based on response reduction factors and the validity of adopted values [3] and [4] recent studies have focused on evaluating the response reduction factors of different structural typologies, 
applying non-linear analysis, [6] and in this research, part of the FEMA P695 methodology [8] has been adopted to validate the reduction factors applied in the Venezuelan seismic code for low-rise RC buildings whose plants have different re-entrants, determining if they lead to satisfactory seismic behavior.

\section{METHODOLOGY FOR THE ASSESMENT}

The methodology of evaluation of the selected models is that described in the document Quantification of building seismic performance factors, which has been published by FEMA (2009) also called FEMA P695. The technical approach includes a combination of normative basics, advanced non-linear range analysis, and risk-based assessment techniques.

Fig. 1 shows the general procedure to be applied, note that five steps are highlighted in grey, it is because they are the steps adapted for the purpose of the assessment performed in this research.

The first step consists into characterize the behaviour. For this purpose, it is necessary to define a set of archetypes that represent the possible variations in the structural models that represent the design space. In the present case, no representative archetypes will be defined, but a set of archetypes will be defined with the possible variations of re-entrants observed more frequently in Venezuela. This is a modification made to the FEMA methodology with the objective of adapting it to the evaluation of the factors reducing the response of structures with this type of irregularity.

The develop of the models, the second step of the methodology, is achieved by means of the modelling of the selected archetypes using a software with the capabilities to perform non-linear analysis taking into consideration the main features of the materials which constitute the structures and other necessary aspects to obtain the seismic response, like the geometric non-linearity.

Table 1: Values of the response reduction factor $\mathrm{R}$, for $\mathrm{RC}$ buildings with different structural typologies.

\begin{tabular}{|c|c|c|c|c|c|}
\hline Ductility level & I & II & III & IIIa & IV \\
\hline ND3 & 6.00 & 5.00 & 4.00 & 6.00 & 2.00 \\
\hline ND2 & 4.50 & 4.00 & N.A. & N.A. & 1.50 \\
\hline ND1 & 2.50 & 2.25 & 2.00 & N.A. & 1.25 \\
\hline
\end{tabular}

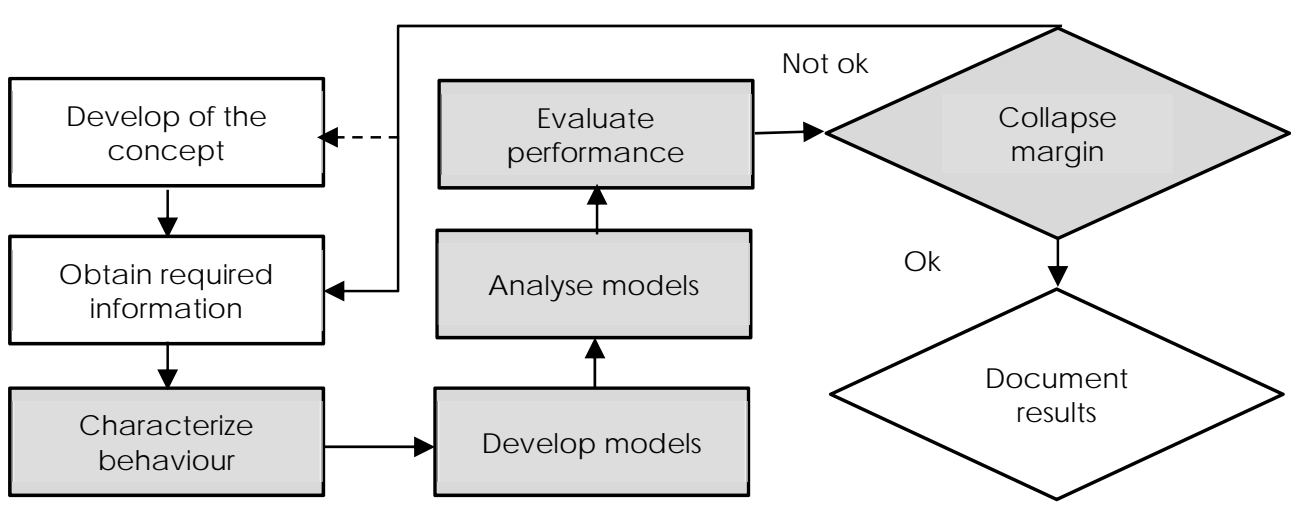

Figure 1: Steps of the FEMA P-695 methodology. 
The analysis of the models is performed in the third step. The loads of the models are defined, including the loads which represent the seismic action. The methodology use two kinds of analysis in order to compute the non-linear response of the structures: pseudo-static (pushover) and incremental dynamic analysis (IDA).

In the fourth step the evaluation of the performance is made. FEMA P695 presents a parameter that is used to perform the evaluation of the response reduction factor $R$, it is the mean collapse ratio $(C M R)$ which is determined as the initial factor to perform the structural safety characterization against collapse; this value must be corrected based on the uncertainties established in the methodology. The mean collapse ratio is the quotient between the values of the acceleration in the mean curve $\hat{S}_{C T}$, obtained in the standard incremental dynamic analysis (IDA), and the acceleration of the maximum considered earthquake, $S_{M T}$ obtained from the elastic design spectrum.

$$
C M R=\frac{\hat{s}_{C T}}{S_{M T}}
$$

Finally, in the fifth step, the values of $C M R$ are compared with the values prescribed by FEMA P-695 for each archetype and for the set of archetypes. If calculated values satisfy the comparison of individual values and of the median, response reduction factors are suitably to perform the seismic design of structures with similar characteristics.

\section{DESCRIPTION OF THE CASES STUDIED}

The set of archetypes selected for the assessment consists in seven low-rise reinforced concrete buildings, designed for high seismic hazard zone (design acceleration of $0.3 \mathrm{~g}$ ) located in a very stiff soil (soil type S2), with a response reduction factor $\mathrm{R}=6$ (high ductility expected), see the elastic and inelastic design spectra in Fig. 2.

Buildings have different plan configurations with three $3.00 \mathrm{~m}$ high stories. The structures of the buildings consist in special moment-resisting frames, with three $6.00 \mathrm{~m}$ length spans in each direction. Buildings are endowed with $25 \mathrm{~cm}$ width RC solid slabs. Fig. 3 summarizes the plan configurations of the seven cases considered herein. Note that cases $2-7$ are plan irregular because the presence re-entrants in the slabs, but cases 2, 4 and 6 are provided with coupling beams in the open side, avoiding the loss of stiffness in such frames, also avoiding the stress concentration in frames and adjacent zones of the slabs, which can occur during the application of lateral loads. The specifications set for the materials are shown in Table 2

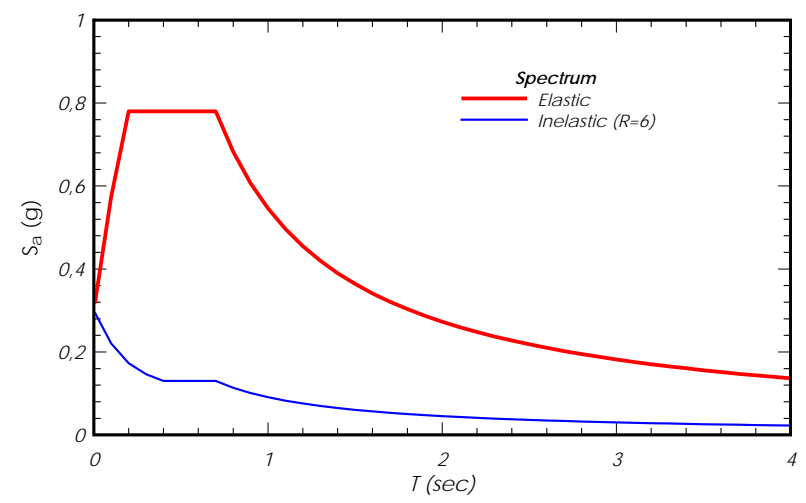

Figure 2: Elastic and inelastic design spectra. 


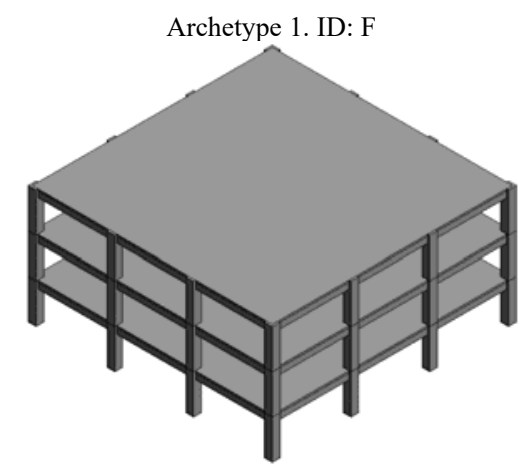

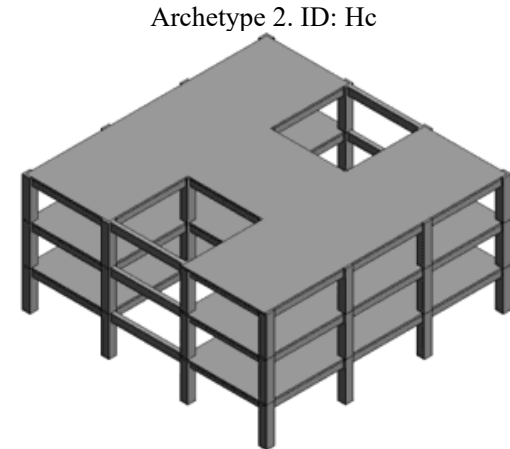

Archetype 4. ID: Uc

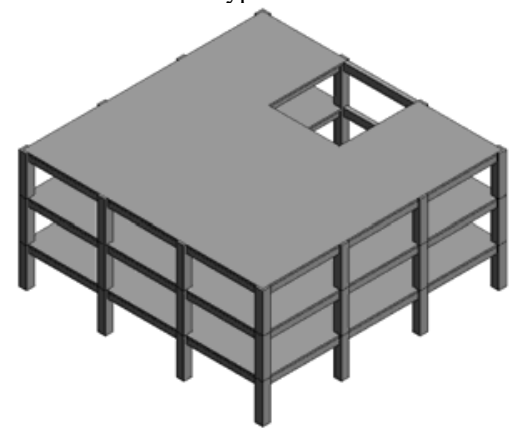

Archetype 6. ID: Cc

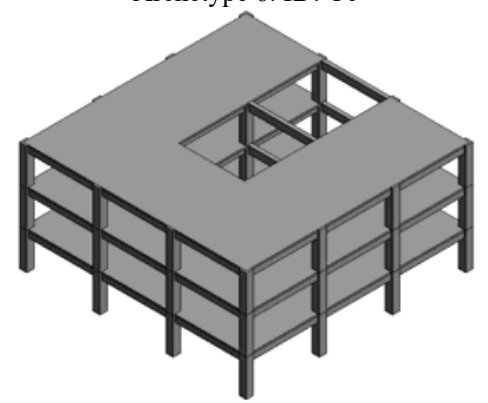

Archetype 3. ID: $\mathrm{Hu}$

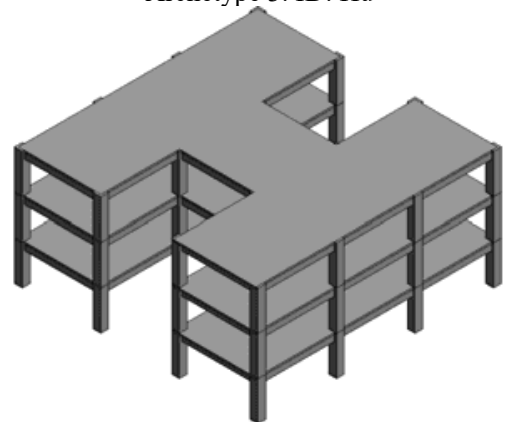

Archetype 5. ID: Uu

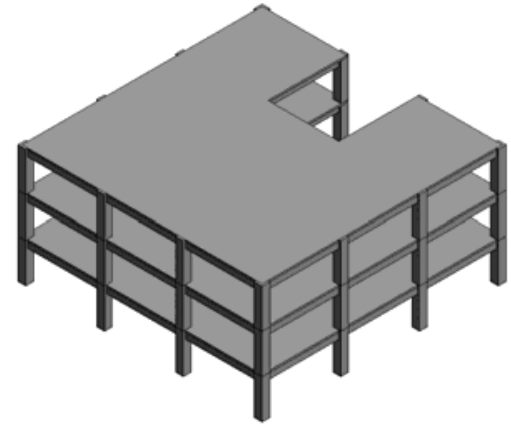

Archetype 7. ID: $\mathrm{Cu}$

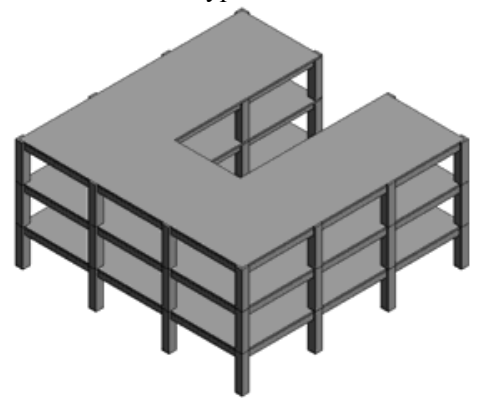

Figure 3: Isometric views of the archetypes. 
Table 2: Materials characteristics used for design.

\begin{tabular}{|l|l|}
\hline Material & Strength \\
\hline Concrete & F'c $=25 \mathrm{MPa}$ \\
\hline Steel & $\mathrm{Fy}=420 \mathrm{MPa}$ \\
\hline
\end{tabular}

Table 3: Records used for non-linear analysis.

\begin{tabular}{|l|l|l|}
\hline \multirow{2}{*}{ Earthquake } & Station & Component \\
\hline \multirow{4}{*}{ Sumatra (Indonesia) } & \multirow{2}{*}{ Sikuai Island } & 090 \\
\cline { 3 - 3 } & & 360 \\
\hline \multirow{5}{*}{ East of Turkey } & $\begin{array}{l}\text { Carbon Canyon } \\
\text { Dam }\end{array}$ & 131 \\
\cline { 3 - 3 } & $\begin{array}{l}\text { Los Angeles } \\
\text { Griffith Observatory }\end{array}$ & 041 \\
\cline { 3 - 3 } & \multirow{2}{*}{ Van Muradiye } & 360 \\
\hline & \multirow{2}{*}{ Bitlis Merkez } & $\mathrm{N}$ \\
\cline { 3 - 3 } & & $\mathrm{S}$ \\
\cline { 3 - 3 } & & $\mathrm{N}-\mathrm{S}$ \\
\cline { 3 - 3 } & & $\mathrm{E}-\mathrm{W}$ \\
\hline
\end{tabular}

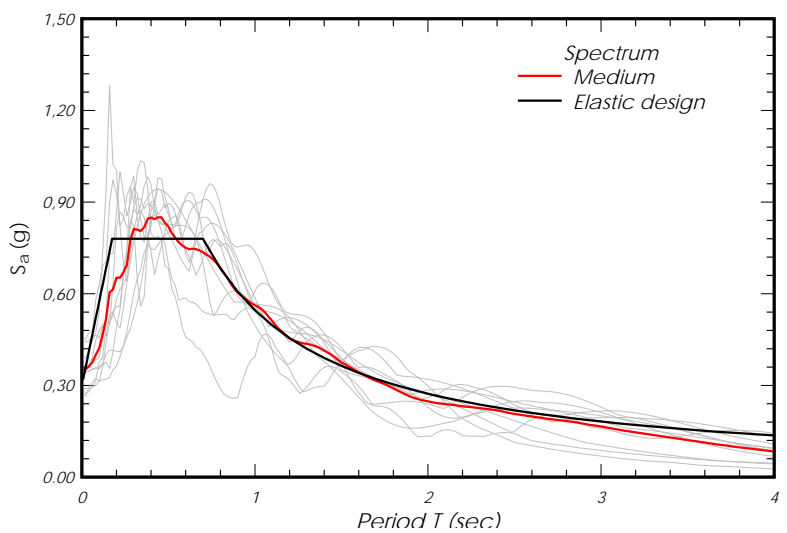

Figure 4: Response, mean response and elastic design spectra.

The analysis, design and detailing of the archetypes was performed according to the current Venezuelan seismic code [9] for residential use. However, interstory drift check was performed using an alternative energy-based procedure, thereby producing stiffer structures than the obtained according to the standard code procedure.

\subsection{Non-linear analysis}

In order to apply the FEMA P-695 methodology, a set of 10 records of destructive ground motions was selected. The characteristics of the set of records is summarized in Table 3 .

The records were modified in order to reach significant damage on the archetypes. A matching procedure that consist in adapt the response spectrum to the elastic design 
spectrum was made for each component of the used seismic record. In Fig. 4, response spectra are shown plotted together with the elastic design spectrum used for the analysis.

The non-linear analysis was then applied considering three-dimensional models of the archetypes, in which the members were discretized into four elements, allowing different zones to be considered in accordance with the confinement provided by the transverse steel. This beneficial effect has been taken into account applying the Mander model. After completing the models of all the archetypes, we proceeded to perform the non-linear analysis. The FEMA P-695 methodology uses the Dynamic Incremental Analysis procedure [12], in which each selected accelerogram starts with its original amplitudes. After obtaining the structural for these records, the amplitudes were increased by means of a linear scaling. At each increment step the maximum response is obtained, which in this case corresponds to the spectral acceleration. In this way, the curves presented in the following section were constructed and allowed to evaluate the response reduction factor.

\section{RESULTS OF THE ASSESSMENT}

Incremental dynamics analyses were performed using Seismo Struct Software; resulting curves are plotted together in Figs 5-11. In order to avoid the subjectivity in the determination of the collapse spectral acceleration $\left(S_{C T}\right)$ a change has been made regarding the methodology: instead of determining the value counting the level of acceleration for the half of the curves achieve the collapse, the median curve for all the curves is computed, then the collapse intensity corresponds to the collapse intensity of the median curve [14].

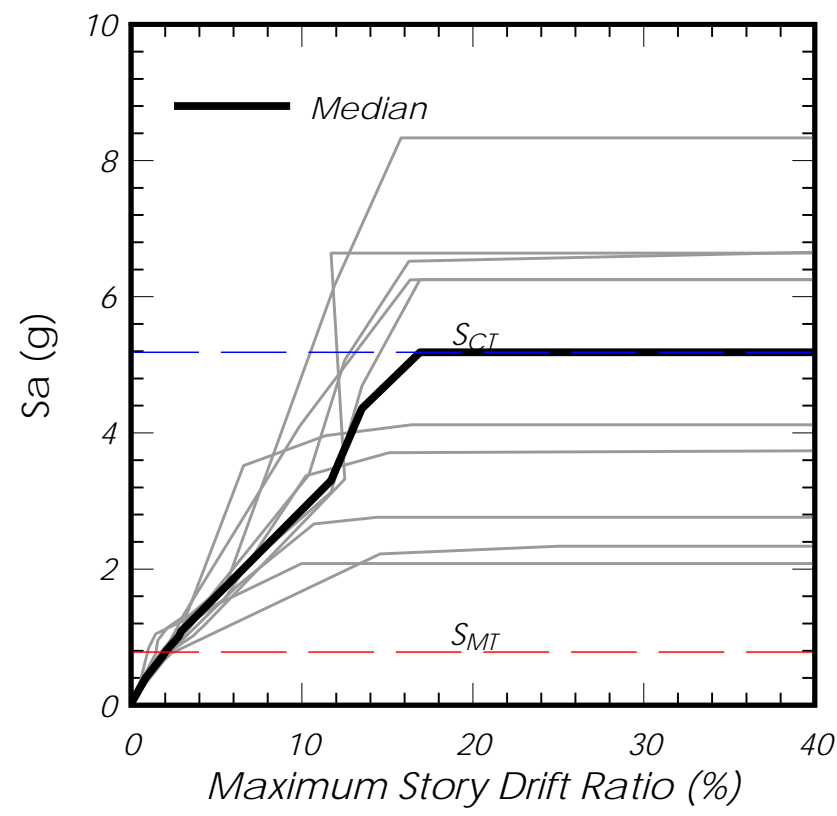

Figure 5: IDA curves of the archetype F. 

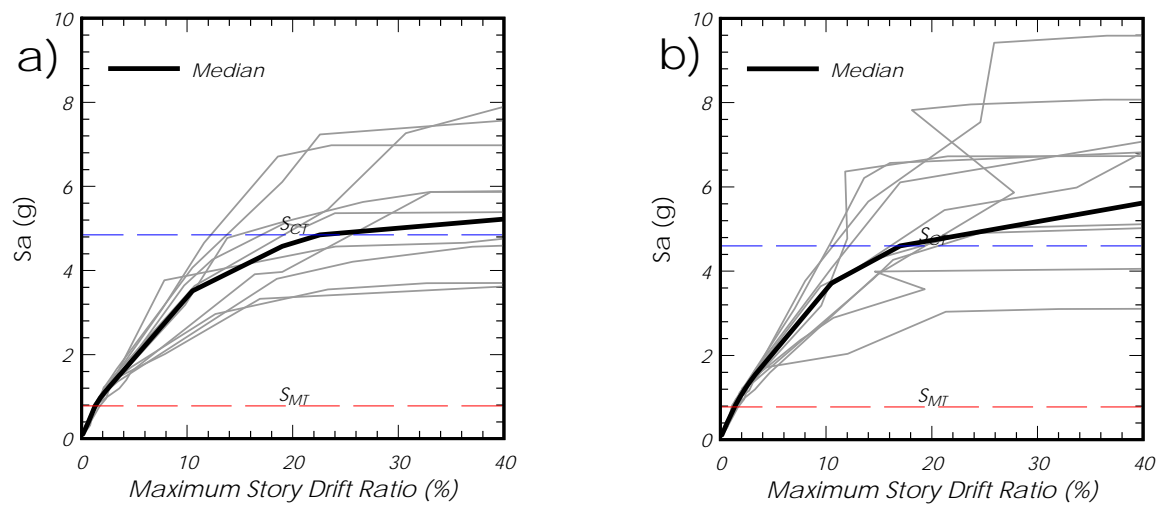

Figure 6: IDA curves of archetype Hc in a) x-direction and; b) y-direction.
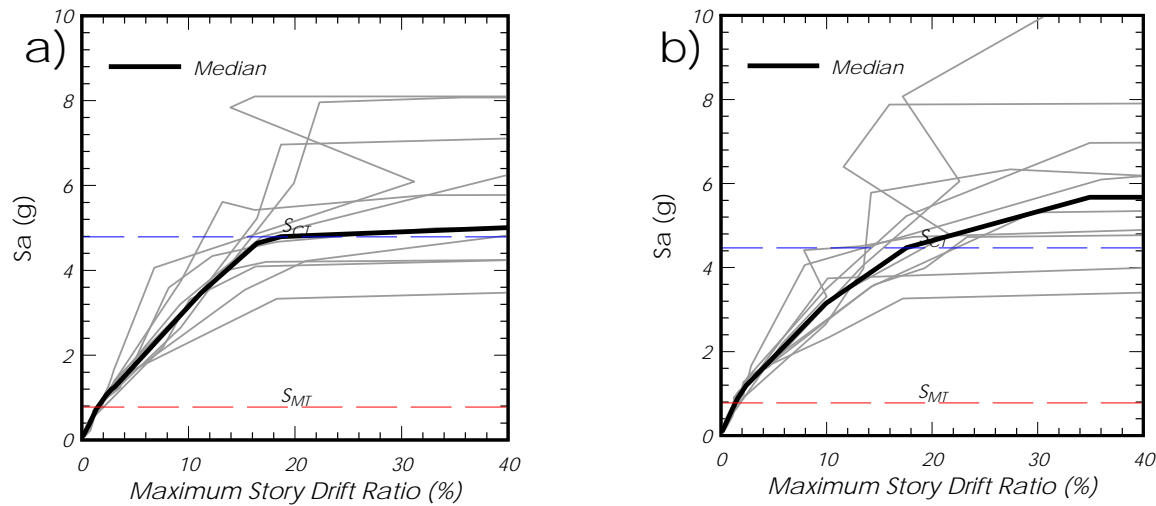

Figure 7: IDA curves of archetype $\mathrm{Hu}$ in a) $\mathrm{x}$-direction and; b) y-direction.
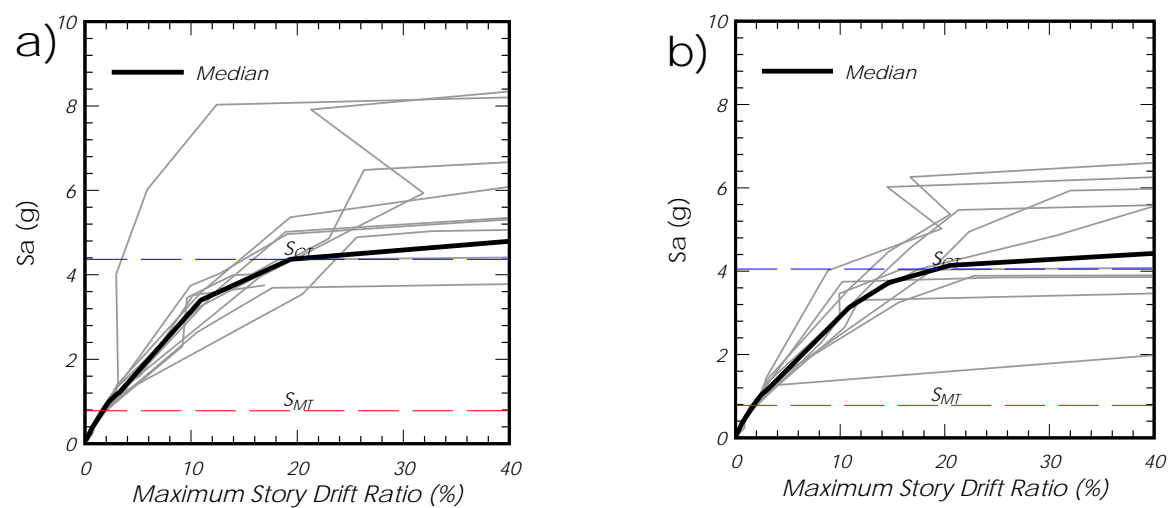

Figure 8: IDA curves of archetype Uc in a) x-direction and; b) y-direction. 

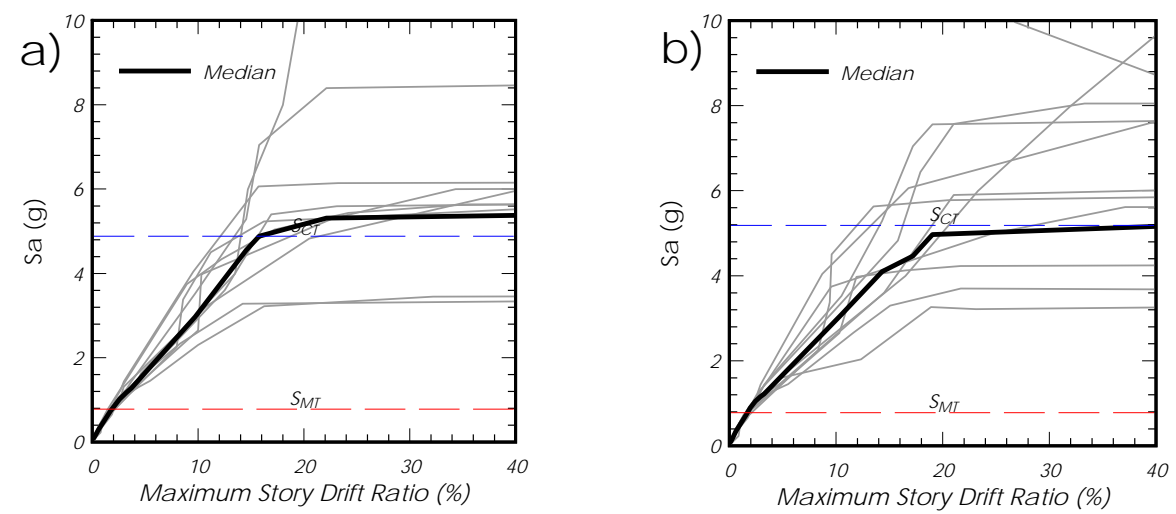

Figure 9: IDA curves of archetype Uu in a) x-direction and; b) y-direction.
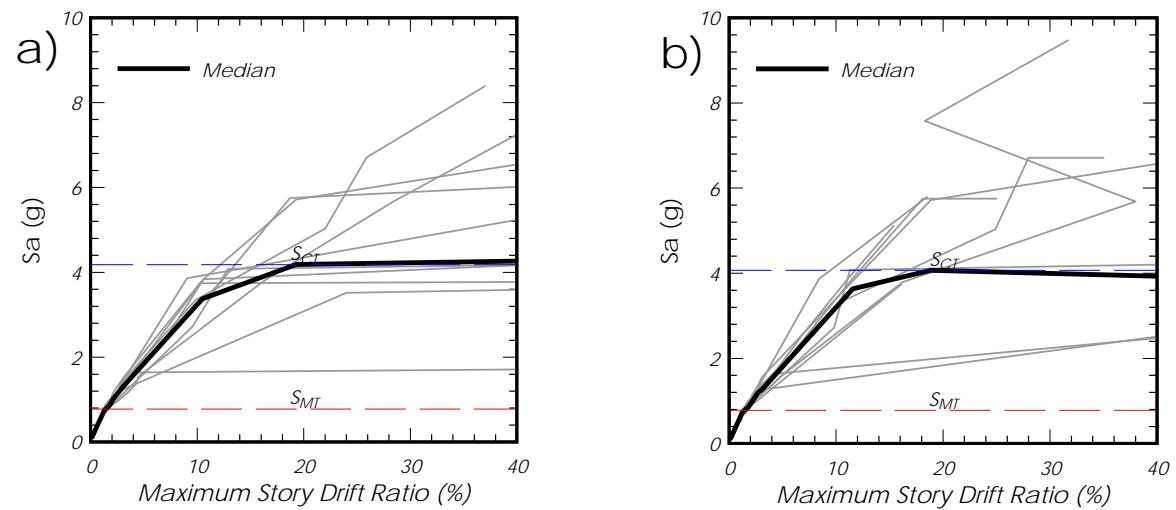

Figure 10: IDA curves of archetype $\mathrm{Cc}$ in a) $\mathrm{x}$-direction and; b) y-direction.
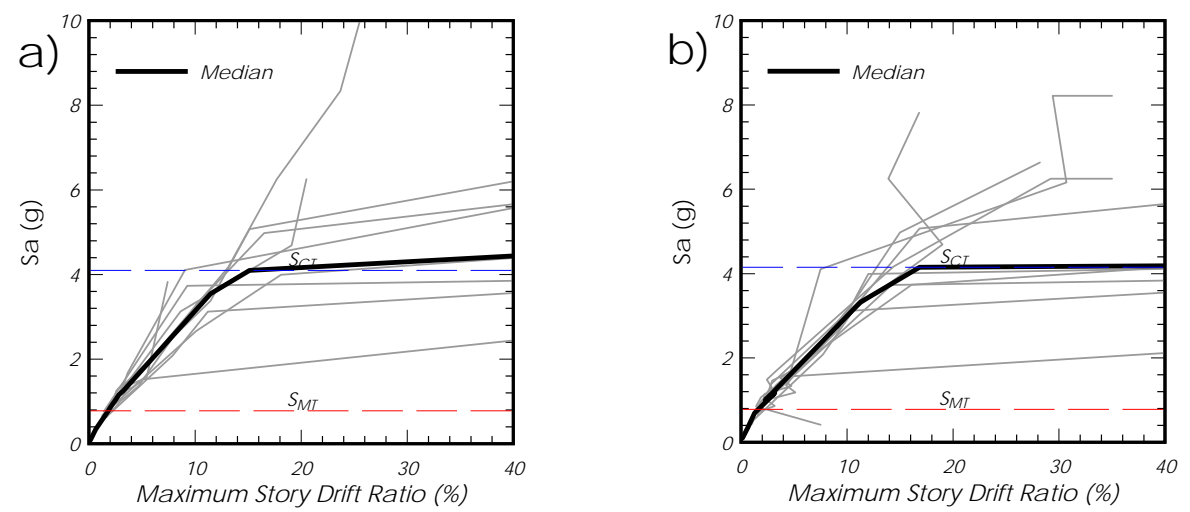

Figure 11: IDA curves of archetype $\mathrm{Cu}$ in a) $\mathrm{x}$-direction and; b) y-direction. 


\subsection{Adjust of the collapse margin ratio}

The values of the collapse margin ratio must be adjusted taking into account the variability of the used records. Thereby, FEMA P-695 establish a set of values of spectral shape factors $(S S F)$, depending on the predominant period of the archetype and the displacement ductility determined by non-linear analysis. Displacement ductility is computed using the capacity curve resulting from pseudo-static non-linear analysis and in order to simplify the task to determine the values of SSF, Fig. 12 contain the tabulated values of FEMA P-695, allowing interpolation. The adjustment is performed according to eqn (2).

$$
A C M R=S S F \cdot C M R
$$

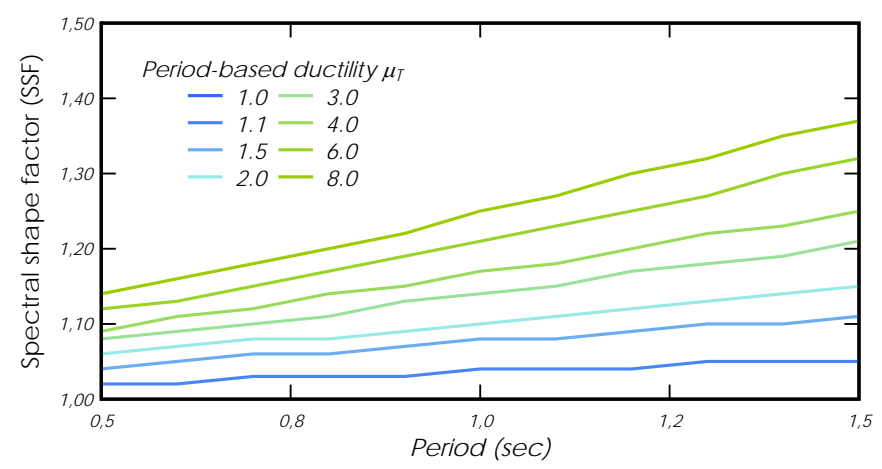

Figure 12: Curves so the spectral shape factors.

Table 4: Values of the collapse margin ratio, spectral shape factor and the adjust collapse margin ratio of the archetypes studied.

\begin{tabular}{|c|c|c|c|c|c|c|}
\hline Archetype ID & Direction & $\mathrm{S}_{\mathrm{CT}}$ & $\mathrm{S}_{\mathrm{MT}}$ & $\mathrm{CMR}$ & $\mathrm{SSF}$ & ACMR \\
\hline $\mathrm{F}$ & Both & 5.19 & 0.78 & 6.65 & 1.13 & 7.49 \\
\hline \multirow{3}{*}{$\mathrm{Hc}$} & $\mathrm{x}$ & 4.85 & 0.78 & 6.22 & 1.11 & 6.91 \\
\cline { 2 - 7 } & $\mathrm{y}$ & 4.60 & 0.78 & 5.90 & 1.10 & 6.50 \\
\hline \multirow{3}{*}{$\mathrm{Hu}$} & $\mathrm{x}$ & 4.79 & 0.78 & 6.14 & 1.12 & 6.90 \\
\cline { 2 - 7 } & $\mathrm{y}$ & 4.47 & 0.78 & 5.73 & 1.13 & 6.45 \\
\hline \multirow{3}{*}{$\mathrm{Uc}$} & $\mathrm{x}$ & 4.37 & 0.78 & 5.60 & 1.14 & 6.37 \\
\cline { 2 - 7 } & $\mathrm{y}$ & 4.05 & 0.78 & 5.19 & 1.12 & 5.81 \\
\hline \multirow{3}{*}{$\mathrm{Uu}$} & $\mathrm{x}$ & 4.88 & 0.78 & 6.26 & 1.13 & 7.07 \\
\cline { 2 - 7 } & $\mathrm{y}$ & 4.97 & 0.78 & 6.37 & 1.12 & 7.12 \\
\hline \multirow{2}{*}{$\mathrm{Cc}$} & $\mathrm{x}$ & 4.18 & 0.78 & 5.36 & 1.12 & 5.99 \\
\cline { 2 - 7 } & $\mathrm{y}$ & 4.07 & 0.78 & 5.22 & 1.11 & 5.80 \\
\hline \multirow{2}{*}{$\mathrm{Cu}$} & $\mathrm{x}$ & 4.10 & 0.78 & 5.26 & 1.14 & 5.99 \\
\cline { 2 - 7 } & $\mathrm{y}$ & 4.15 & 0.78 & 5.32 & 1.13 & 6.01 \\
\hline
\end{tabular}




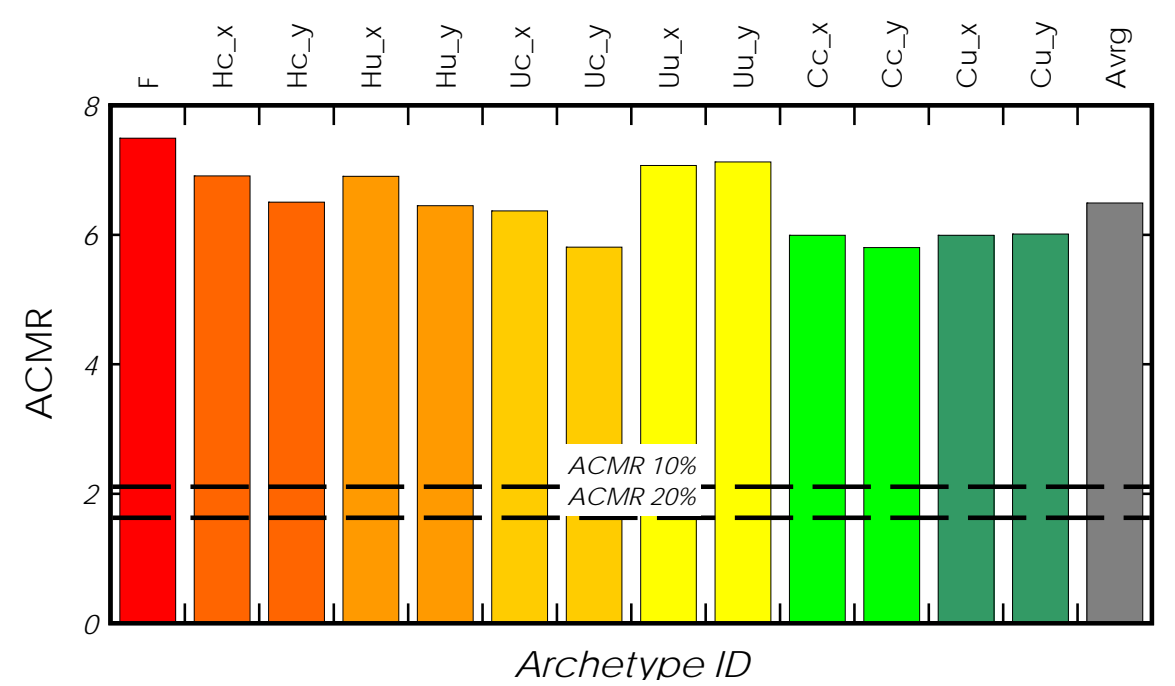

Figure 13: Values of the adjusted collapse margin ratio (ACMR) of the archetypes studied.

Table 4 summarizes the values of $C M R$ computed from IDA curves, the values of SSF interpolated from Fig. 12 and the values of ACMR.

In Fig. 13 the values of the ACMR of each archetype in both direction of analysis is summarized. Firstly, note that exists a very large margin between the value of the adjusted collapse margin ratio $\left(A C M R_{i}\right)$ and the acceptable collapse margin ratio $\left(A C M R_{20 \%}\right)$ determined for the structural models according to FEMA P-695. On the other hand, the average of the values of the adjusted collapse margin ratio $(\overline{A C M R})$ is greater than the value prescribed for the $A C M R_{10 \%}$. The subscript of the values of the acceptable collapse margin ratio represent the percentage of exceedance probability.

\section{CONCLUSIONS}

The used methodology is an adaptation of the general methodology of FEMA P-695, originally formulated in order to assess new structural typologies.

The ACMR values of the individual archetypes far separate the acceptable values obtained by applying the FEMA P695 methodology for a $20 \%$ probability of exceedance. Similarly, the average of the values of the adjusted collapse margin ratio $(\overline{A C M R})$ of the set of archetypes is much larger than the acceptable value considering a $10 \%$ probability of occurrence. According to these results, it can be stated that the response reduction factors prescribed by the Venezuelan seismic standard successfully exceed the evaluation, and the response of similar structures, designed with these response reduction factors, can be expected to behave in a safe way to earthquakes with an intensity comparable to that of the design elastic spectrum.

Although the archetypes studied here presented irregularity characteristics that did not need to apply penalties to the response reduction factors, the value prescribed by the Venezuelan seismic code $(R=6)$ is safe according to the applied methodology.

\section{ACKNOWLEDGEMENTS}

First author would acknowledge Pontificia Universidad Católica de Valparaíso, for the support to the preparation of this paper. Authors also acknowledge the support of CDCHT of 
the Universidad Centroccidental Lisandro Alvarado and the Network of the CIMNE Classrooms, where this research was developed.

\section{REFERENCES}

[1] De Stefano, M. \& Mariani, V., Pushover Analysis for Plan Irregular Building Structures. in Perspectives on European Earthquake Engineering and Seismology. Geotechnical, Geological and Earthquake Engineering, Springer: Heidelberg, pp. 429-448, 2014.

[2] Covenin 1756-2001, Code for earthquake-resistant buildings. Caracas: Fondonorma, 2001.

[3] Paulay, T., A simple seismic design strategy based on displacement and ductility compatibility. Earthquake Engineering and Engineering Seismology, 1(1), pp. 51-67, 1999.

[4] Priestley, M.N.J., Myths and Fallacies in Earthquake Engineering. IUSS Press: Pavia, 2003.

[5] Sánchez-Ricart, L. \& Plumier, A., Parametric study of ductile moment-resisting steel frames: A first step towards Eurocode 8 calibration. Earthquake Engineering and Structural Dynamics, 37(7), pp. 1135-1155, 2008.

[6] Elnashai, A. \& Mwafy, A., Over strength and force reduction factors of multi-storey reinforced-concrete buildings. The Structural Design of Tall Buildings, 11(5), pp. 329-351, 2002.

[7] Vielma, J.C., Barbat, A.H. \& Oller, S., Seismic safety of low ductility structures used in Spain. Bulletin of Earthquake Engineering, 8, pp. 135-155, 2010.

[8] FEMA, Quantification of building seismic performance factors. Federal Emergency Management Agency, Washington D.C., 2009.

[9] Fondonorma, 1753-2006, Design and construction of structural concrete works. Caracas: Fondonorma, 2006.

[10] Vielma, J.C., Barbat, A.H. \& Oller, S., Seismic response of the RC framed buildings designed according to Eurocodes. Computational Methods in Earthquake Engineering, eds N. Lagaros, M. Papadrakakis \& M. Fragiadakis, Springer: Heildelberg, pp. 121-135, 2010.

[11] Mander, J.B., Priestley, M.J.N. \& Park, R., Observed stress-strain behaviour of confined concrete. Journal of Structural Engineering (ASCE), 114(8), pp. 1827-1849, 1988.

[12] Vamvatsikos, D. \& Cornell, A., Incremental dynamic analysis. Earthquake Engineering and Structural Dynamics, 31(3), pp. 491-514, 2002.

[13] Seismosoft, SeismoStruct v7.0 - A computer program for static and dynamic non-linear analysis of framed structures, 2014. [Online].

[14] Vielma J.C. \& Mulder, M.M., Procedure for assess the displacement ductility based on seismic collapse threshold and dissipated energy balance. Proceedings of the XVI World Conference on Earthquake Engineering, Santiago de Chile, 2017.

[15] Elnashai, A. \& Di Sarno, L., Fundamentals of Earthquake Engineering, John Willey and Sons: Chichester, 2008.

[16] Vielma, J.C. \& Cando, M.A., Influence of P-delta effect on ductility of SMRF steel buildings. The Open Civil Engineering Journal, 9(1), pp. 351-359, 2015. 